\title{
Role of Doppler Ultrasound in Prediction of Perinatal Outcome in IUGR
}

\author{
Gurusiddanagowda K. Chinnappanavar ${ }^{1}$ \\ ${ }^{1}$ Associate Professor, Department of Radiodiagnosis, Sree Narayana Institute of Medical Sciences Chalakka, North Paravur \\ Road, Ernakulam District, Kerala 683594, India
}

Corresponding author: Gurusiddanagowda K. Chinnappanavar, Associate Professor, Department of Radiodiagnosis, Sree Narayana Institute of Medical Sciences Chalakka, North Paravur Road, Ernakulam District, Kerala 683594, India

DOI: http://dx.doi.org/10.21276/ijcmsr.2020.5.1.15

(c) BY-NC-ND

How to cite this article: Gurusiddanagowda K. Chinnappanavar. Role of Doppler ultrasound in prediction of perinatal outcome in IUGR. International Journal of Contemporary Medicine Surgery and Radiology. 2020;5(1):A65-A67.

\section{A B S T R A C T}

Introduction: The literature available shows that, the Umbilical artery Doppler has proven to be useful for predicting the neonatal outcome in IUGR foetuses. The available reports have shown that the abnormal umbilical artery Doppler ultrasound increases the perinatal mortality and morbidity. So the current study aimed at identifying the predictive value of umbilical artery Doppler in IUGR foetuses in relevance to perinatal outcome.

Material and Methods: Prospective study was conducted in department of radiodiagnosis, Kerala Medical College, for one year between June 2015 to May 2016. One hundred singleton pregnancies convoluted by IUGR beyond 32 weeks were exposed for Doppler study. Perinatal conclusion in terms of baby outcome, birth weight, earlyneonatal death, admission in NICU and duration of admission were analysed. SPSS Version 22 was used for analysis.

Results: This study has shown that, oligohydramnios (75\%) was the main reason for termination of pregnancy in category I and II. Other reasons were $10 \%$ for uncontrolled hypertension and $6 \%$ for post term were the chief indicators for termination of pregnancy. Fifty percent were delivered vaginally and $50 \%$ by lower segment cesarean section in this study. Birth weight of the babies varied from $800 \mathrm{gm}$ to $2.5 \mathrm{Kg}$. Perinatal mortality in our study is $20 \%$ which includes $9 \%$ of intrapartum mortality and $11 \%$ of neonatal mortality and perinatal morbidity is $24 \%$.

Conclusions: The results of present study evidently established the efficacy of umbilical artery Doppler ultrasound in prediction of the fetal outcome. A better method is needed urgent basis in order to improve the predictive accuracy of this tool to to assess the wellbeing of the IUGR foetuses.

Keywords: IUGR, Perinatal Mortality and Morbidity, Oligohydramnios, LSCS, Doppler Ultrasound, Still Born.

\section{INTRODUCTION}

Intra Uterine Growth Restriction (IUGR) is often defined as estimated fetal weight less than $10^{\text {th }}$ percentile for that gestational age. Maternal and fetal genetic makeup and blood supply to the fetus decides the growth of the fetus rest on the genetic potential. The studies available have shown that, the incidence of IUGR varies between 3-10\% of all pregnancies by using diagnostic criteria. ${ }^{1}$ At any gestational age, infants with low birth weight have relatively high morbidity and mortality. ${ }^{1,2}$ Previous studies have shown that, the babies with low birthweight babies are known to be susceptible for fetal demise, birth asphyxia, meconium aspiration, hypoglycaemia, hypothermia, respiratory distress syndrome. There association between IUGR and later development of metabolic syndrome comprising of arterial hypertension, coronary artery heart disease, dyslipidemia, visceral obesity, impaired glucose tolerance and Type 2 diabetes mellitus is well established. ${ }^{3}$ Traditionally, the confirmation of IUGR is conducted with two dimensional ultrasonogram. The abdominal circumference of less than $5^{\text {th }}$ percentile or estimated, fetal weight less than $10^{\text {th }}$ percentile confirms intra uterine growth retardation (IUGR). The estimated fetal weight can be better predicted by Doppler blood flow studies alone. ${ }^{4,5}$ It is non-invasive and is capable if depicting the hemodynamic changes occurringin foetuses. The literature pertaining to the use of Doppler velocimetry in decision of not only optimum time of delivery, but also optimum mode of delivery. This study was undertaken with the aim of to assess the role of Doppler ultrasound in predicting the mortality and morbidity of foetuses with IUGR.

\section{MATERIAL AND METHODS}

A prospective analytical study was conducted in Department of Radiodiagnosis, in Kerala Medical College, Cherpulassery, Pallakad between June 2015 to May 2016. About hundred singleton pregnancies complexed with intrauterine growth restriction of beyond 32 weeks were included in the study. This study excludes Multiple pregnancies, patients with irregular menstrual cycles without dating scan in the first trimester and intra uterine growth restriction complicated 
by abruption placenta and uterine rupture. Toshiba Nemio colour Doppler machine was used for this study. A curvilinear probe with $3.5 \mathrm{MHz}$ was used.

Demographic characteristic of the patients, details of last menstrual period and high-risk factors including chronic hypertension, gestational hypertension, renal disease, collagen vascular disease, thyroid disorders, anaemia, heart disease were noted in predesigned proforma. IUGR was suspected when there was growth lag of 4 weeks between gestational age and uterine fundal height on palpation. These patients were tested with two dimensional ultrasonogram. Biparietal diameter (BPD), Head circumference, Abdominal circumference $(\mathrm{AC})$ and Femur length (FL) were noted by using the machine. Haddlock formula was used to estimate fetal weight by a builtin software in the ultrasound machine. Intrauterine growth restricted fetuses were recognised by using percentile charts when the abdominal circumference is less than $5^{\text {th }}$ percentile and the projected fetal weight is less than $10^{\text {th }}$ percentile for that gestational age. Umbilical artery Doppler velocimetry was used to determine Umbilical artery RI, PI and S/D ratio after diagnosing IUGR.

The IUGR foetuses were categorized in to three categories using percentile charts for each index. Category I- Umbilical artery Doppler indices less than $95^{\text {th }}$ percentile for that gestational age.

Category II- Umbilical artery Doppler indices more than $95^{\text {th }}$ percentile for that gestational age. But umbilical artery had forward diastolic flow.

Category III- Absent diastolic flow or reverse end diastolic flow.

The mode of delivery, birth weight of the baby, APGAR at 1 and 5 minutes, admission in NICU were renowned. Stillborn fetuses and fetuses who died in early neonatal period were noted.

\section{RESULTS}

As per table 1 doppler ultrasound showed that, 57\% were born normally and $43 \%$ were born as IUGR. On the basis of absent diastolic flow, about $43 \%$ of the foetuses were classified in to two categories where, $30 \%$ belonged to category II and $13 \%$ to category III.

Oligohydramnios (75\%) was the main reason for termination of pregnancy in category I and II. Ten percent of the pregnancies were terminated because of uncontrolled hypertension and $4 \%$ were terminated for post term. In the category III group, absent diastolic flow in the umbilical artery was the sign in $2 \%$ of the cases.

Birth weight of the babies varied from 800 gms $-2.5 \mathrm{Kgs}$. About $62.7 \%$ of category I and $28.6 \%$ of category II, baby weight was more than $2 \mathrm{kgs}$. None of the baby's birth weight was more than $2 \mathrm{~kg}$ and $80 \%$ of babies considered less than $1.5 \mathrm{~kg}$ in category III.

There are about $11 \%$ early neonatal deaths in the NICU. The causes were credited to necrotising enterocolitis, Intraventricular haemorrhage and hypoxic ischemic encephalopathy. General $80 \%$ of the category III group had poor perinatal outcome were due to still birth or as early

\begin{tabular}{|l|c|}
\hline IUGR cases & Number (\%) \\
\hline Normal & $57(57)$ \\
\hline Abnormal & $43(43)$ \\
\hline Categories & $57(57)$ \\
\hline I & $30(30)$ \\
\hline II & $13(13)$ \\
\hline III & \multicolumn{2}{|c|}{ Table-1: Number and Grading of IUGR cases according to } \\
\hline \multicolumn{2}{|c|}{ Doppler studies } \\
\hline
\end{tabular}

\begin{tabular}{|l|c|c|c|}
\hline Indication & Category I & Category II & Category III \\
\hline Oligohydramnios & 55 & 20 & \\
\hline Uncontrolled HTN & 5 & 4 & 1 \\
\hline Post term & 1 & 3 & \\
\hline Eclampsia & 1 & & \\
\hline Gestational HTN & 3 & 2 & 1 \\
\hline HELLP Table-2: Indication for Termination \\
\hline \multicolumn{4}{|l|}{} \\
\hline
\end{tabular}

\begin{tabular}{|l|c|c|c|}
\hline Birth Weight (kg) & I & II & III \\
\hline$<1.5$ & 6 & 6 & 6 \\
\hline $1.5-2.5$ & 16 & 6 & 6 \\
\hline$>2.5$ & 35 & 18 & 1 \\
\hline \multicolumn{2}{|c|}{ Table-3: Birth Weight of Study Group category wise } \\
\hline
\end{tabular}

\begin{tabular}{|l|c|c|c|}
\hline Admission to NICU & I & II & III \\
\hline 1-4 days & 13 & 4 & 2 \\
\hline $5-7$ days & 2 & 2 & 1 \\
\hline$>7$ days & \multicolumn{3}{|c|}{ Table-4: Neonatal Morbidity category wise } \\
\hline \multicolumn{3}{|c|}{} \\
\hline
\end{tabular}

\begin{tabular}{|l|c|c|}
\hline Doppler & Adverse & Good \\
\hline Abnormal & 33 & 10 \\
\hline Normal & 17 & 40 \\
\hline Table-5: Perinatal Outcome among the study subjects based \\
on Doppler ultrasound \\
\hline
\end{tabular}

\begin{tabular}{|l|c|c|c|}
\hline Outcome & I (57) & II (30) & III (13) \\
\hline Still born & 1 & 2 & 3 \\
\hline Early neonatal death & 5 & 6 & 4 \\
\hline Perinatal mortality & $8 \%$ & $26 \%$ & $85 \%$ \\
\hline Perinatal morbidity & 20 & 15 & 1 \\
\hline Adverse Outcome & 26 & 23 & 8 \\
\hline \multicolumn{2}{|c|}{ Table-6: Perinatal Outcome Category wise } \\
\hline
\end{tabular}

neonatal death. Neonatal morbidity was determined by using admission and duration of stay in NICU. A total of 26 babies were admitted in NICU ( $15 \%$ of category I, $7 \%$ of category II and $4 \%$ of category III). Hypoxic ischemic encephalopathy, respiratory distress, necrotizing enterocolitis, hypoglycaemia, meconium aspiration syndrome and hyperbilirubinemia were the main reason for admission to NICU.

Though IUGR fetuses were identified with two dimensional ultrasonogram, it does not forecast the perinatal outcome. Hence these IUGR fetuses wereexamined with umbilical 
artery Doppler ultrasound. Abnormal showed 33\% has adverse effect. $40 \%$ Normal showed good doppler.

Overall perinatal mortality in our study was $20 \%$ which comprises $9 \%$ of intrapartum mortality and $11 \%$ of neonatal mortality. Perinatal morbidity was $24 \%$. Perinatal mortality was higher in absent or reverse diastolic flow group in Category III.

\section{DISCUSSION}

The present study was prearranged to determine the IUGR and Perinatal outcome. Mean gestational age when the patients were identified as IUGR was 36.8 weeks. In the study population patients with smaller gestational age $(<32$ weeks $)$ with IUGR were excluded in order to evade the influence of preterm birth in perinatal morbidity and mortality. This study had shown that, $8 \%$ of category II and $2 \%$ of category III patients had gestational hypertension. Studies by Bynn YJ et al and Sharma U et al presented gestational hypertension as a predisposing factor for 30\%patients. ${ }^{6,7} \mathrm{In}$ Deshmukh A et al study $78.6 \%$ of low diastolic flow patients and $82.35 \%$ of reverse diastolic flow patients were inclined by hypertensivedisorder. ${ }^{8} 75 \%$ patients have oligohydramnios as the sign of termination. Deshmukh A et al stated that $64.30 \%$ of low diastolic flow group and82.35\% of ADF/ RDF group had oligohydramnios. ${ }^{8}$ This study had shown that, $20 \%$ of category II had oligohydramnios. In category III patients, 70\% had absent diastolic flow and 30\% had reversal of flow and pregnancy was ended. About 50\% in this study were delivered vaginally and $50 \%$ by LSCS. In category I, 52.5\% were delivered vaginally and $47.5 \%$ delivered by LSCS. In other categories vaginal delivery was the mode of delivery. About $69.5 \%$ in category II and $90 \%$ in category III were delivered vaginally in this study. This study had shown an overall perinatal mortality of $19 \%$ which included $8 \%$ of intrapartum mortality and $1 \%$ of neonatal mortality. Perinatal morbidity was $24 \%$ in this study. This is in agreement with Deshmukh et al study where perinatal mortality and morbidity were $18 \%$ and $49 \%$ respectively. ${ }^{8}$ This study had demonstrated higher perinatal mortality in absent or reverse diastolic flow group. Absent diastolic flow in the umbilical artery was related to increased perinatal mortality, the mortality rate was $100 \%$ in Narulla $\mathrm{H}$ et al, Lakhar BN et al, Mohamed K et al..$^{9.10,11}$ Bhatt et al had reported $50 \%$ mortality. ${ }^{12}$ In this existing study, 80\%perinatal mortality occurred in category III. In category II, the perinatal mortality was $20 \%$. The mortality rate would have reached higher rate as in absent group change in the diastolic flow of the umbilical artery was followed up in category II. In category I, above supposed studies were in support of good perinatal outcome with $100 \%$ negative predictive value. In the current study, these patients also had opposing perinatal outcome in both mortality (7.5\%) and morbidity (23.9\%). Cochranedatabase systematic review (2000) in high risk pregnancies had reported that, use of Doppler ultrasonogram in high risk pregnancies seem to improve several obstetric outcomes inhelping to reduce perinatal death. ${ }^{13}$

\section{CONCLUSION}

The results of the present study clearly established the efficacy of Doppler ultrasound in forecasting the fetal outcome. Identification of intra uterine growth restricted fetuses due to uterplacental insufficiency is supportive in planning the antenatal fetal surveillance. Umbilical artery Doppler study can identify the changes in the umbilical artery which in turn predicts the confrontation offered. Hence Doppler ultrasound is one of the effective tool for doing antenatal fetal surveillance in IUGR fetuses.

\section{REFERENCES}

1. Bhide, Arulkumaran, Damania, Daftary. Arias'Practical guide to high-risk pregnancy and delivery:A South Asian perspective, 4 th ed. 2015:88-103.

2. McIntire DD, Bloom SL, Casey BM, Leveno KJ.Birth weight in relation to morbidity and mortalityamong newborn infants. New England J Med.1999;340(16):1234-8.

3. Cemace Perinatal Mortality 2008. London, UK:Centre for Maternal and Child Enquiries; 2010.

4. Ott WJ. Intrauterine growth restriction and Dopplerultrasonography. J Ultrasound Med.2000;19(10):661-5.

5. Alfirevic Z, Stampalija T, Gyte GM. Fetal andumbilical Doppler ultrasound in high-riskpregnancies. Cochrane Database Syst Rev.2010;(1):CD007529.

6. Byun YJ, Kim HS, Yang JI, Kim JH, Kim HY,Chang SJ. Umbilical artery Doppler study as a predictive marker of perinatal outcome in pretermsmall for gestational age infants. Yonsei Med J.2009;50(1):39-44.

7. Urmila S, Beena B. Triple vessel wave pattern byDoppler studies in normal and high risk pregnanciesand perinatal outcome. J Obstet Gynecol India.2010;60(4):312-6.

8. Deshmukh A, Neelu S, Suneeta G. Significance ofumbilical artery Doppler velocimetry in the perinataloutcome of the growth restricted fetuses. J ObstetGynecol. 2010;60(1):38-43.

9. Narulla H, Kapila AK, Kaur MM. Cerebral andumbilical arterial blood flow velocity in normal andgrowth retarded pregnancy. J Obstet Gynecol India.2009;59(1):47-52.

10. Lakhkar BN, Rajagopal KV, Gourisankar PT.Doppler prediction of adverse perinatal outcome inPIH and IUGR. Indian Radiol Imag. 2006;16(1):109.

11. Khalid M, Wahab S, Khalid VK, Haroon S,Sabzposh NA. Doppler indices in prediction of fetaloutcome in hypertensive pregnant women. Nepal JObstet Gynaecol. 2015;6(1):28-34.

12. Bhatt CJ, Arora J, Shah MS. Role of color Dopplerin pregnancy induced hypertension (a study of 100cases). Indian J Radiol Imag. 2003;13(4):417.

13. Neilson JP, Alfirevic Z. Doppler ultrasound for fetalassessment in high risk pregnancies. CochraneDatabase Syst Rev. 2000;(2):CD 000073.

Source of Support: Nil; Conflict of Interest: None

Submitted: 22-11-2019; Accepted: 11-12-2019; Published online: 01-02-2020 